\title{
Avaliação da Participação de Professores de Biologia em Curso de Formação Continuada a Distância: Dificuldades e Perspectivas

\section{Keiciane Canabarro Drehmer} Marques $^{1 *}$

Lucas Santiago dos Santos ${ }^{1}$ Luiz Caldeira Brant de Tolentino Neto ${ }^{1}$

${ }^{1}$ Universidade Federal de Santa Maria. Av. Roraima nº 1000 , Cidade Universitária -Bairro Camobi -Santa Maria - RS -Brasil.

keicibio@gmail.com *

\section{Resumo}

Este estudo avaliou a participação de professores de Biologia em um curso de formação continuada na modalidade a distância (EaD). Foram analisados os motivos pela busca desse curso, época do ano mais propícia, as dificuldades e razões para evasão. Os dados foram coletados por meio de entrevistas semiestruturadas de forma triangulada, dois entrevistadores e um entrevistado. Os docentes entrevistados foram professores envolvidos em um curso de formação continuada em EaD divididos em três grupos: inscritos, evadidos no decorrer do curso e concluintes. Os resultados mostram que há interesse dos docentes em participar de cursos de formação continuada EaD devido, sobretudo, à flexibilidade de horários diante da jornada de trabalho. A temática do curso é um motivador para participação dos professores; a época mais propícia é no primeiro semestre do ano. A evasão de alguns cursistas ocorreu pela falta de tempo, dedicado prioritariamente às atividades na escola. Os resultados obtidos nessa pesquisa podem auxiliar na construção de cursos de formação continuada para professores a distância.

Palavras-chave: Educação a Distância, Professores de Biologia, Formação continuada. 


\title{
Evaluation of the Participation of Biology Teachers in an On-Line Course: Difficulties and Perspectives
}

\begin{abstract}
This study evaluated the participation of biology teachers in an on-line in-service formation course (ead). We analyzed the purpose of choosing this course, the most favorable period of year and evasion motives. The reports of teachers were collected by a semi structured interview in triangulated way, two interviewers and one interviewed. The interviewed were teachers involved in a on-line inservice formation courses, divided in three groups: subscribed teachers, evaded throughout the course and concluding. The results shown there is interest from the teachers to participate in on-line in-service courses with distance learning, due to the flexibility of time facing the work journey. The theme of the course is a motivation factor for the participation of the teachers and the most favorable period is in the first semester of the year. The evasion of some teachers occurred due to lack of time, devoted primarily to activities at school. The results obtained in this research may help building on-line courses of in-service formation for teachers.
\end{abstract}

Keywords: On-line education, Biology teachers, In-service formation.

\section{Introdução}

A formação contínua dos profissionais da educação tem como objetivo o aprimoramento acadêmico e a busca pelo desenvolvimento profissional. Durante a atuação docente, os professores deparam-se com a necessidade de aperfeiçoamento acerca de metodologias e de seus componentes curriculares; os cursos de formação continuada ajudam a suprir parte dessa carência auxiliando nas renovações sobre práticas pedagógicas levando os professores a reestruturar e aprofundar conhecimentos adquiridos na formação inicial.

Diante da situação de muitos professores, como falta de tempo, altas jornadas de trabalho, a falta de recursos para deslocamento e até mesmo o custo de algumas formações são fatores que dificultam a formação continuada na modalidade presencial (Garcia, 2014).

Como forma alternativa, a modalidade Educação a Distância (EaD) tem expandido seu alcance, apresentando vantagens no processo educativo, como liberdade de horário, redução de custos, flexibilidade de local para trabalhar, capacidade de autonomia e autoaprendizagem (Belloni, 2003), possibilitando assim maior abrangência de educadores em suas práticas formativas em ambientes virtuais de aprendizagem. Garcia (2012) sugere que as universidades públicas podem auxiliar nos programas de formação contínua para professores utilizando a Educação a Distância por meio de abordagens inovadoras para essa formação.

De acordo com a Lei de Diretrizes e Bases da Educação Nacional (Lei n 9.394/96), Artigo 87, § 3, III - "realizar programas de capacitação para todos os professores em exercício, utilizando também, para isto, os recursos da Educação a Distância" - percebe-se um incentivo à realização de capacitações para os professores por EaD, ou seja, deve-se utilizar as diferentes possibilidades para auxiliar no processo de formação continuada para os educadores. A constante atualização dos professores é algo indispensável para uma prática docente com qualidade e parte essencial da vida profissional dos educadores. Entendemos que, além de corrigir falhas e preencher lacunas provenientes da formação inicial, torna-se o meio pelo qual 
o professor poderá se manter atualizado, em vista da constante evolução do conhecimento (Salvador et al., 2010).

O educador da área de Biologia apresenta essa necessidade de atualização mais conspícua - cada vez maior - pelo comportamento dinâmico da ciência e tecnologia; por isso é preciso que o professor esteja em constante movimento de ação-reflexão-ação, em um processo contínuo de formação (Bonzanini; Bastos, 2009). Pesquisas de Salvador et al. (2010; 2012) apontam que a modalidade EaD como estratégia de aprimoramento tem se mostrado uma ótima opção, pois a procura de professores por cursos de formação continuada em Ciências e Biologia nessa modalidade tem aumentado nos últimos anos; os pedidos de inscrições em cursos em EaD, no ano de 2009, mais que dobrou em relação ao ano 2006.

Conforme a situação apresentada por Garcia (2014), ocorre uma diferenciação na formação presencial em relação à formação a distância, uma vez que na primeira o professor muitas vezes assume uma postura mais passiva e memorizadora, enquanto a formação contínua a distância requer um professor mais ativo, participativo, crítico e colaborativo, auxiliando também na questão motivacional e autônoma do docente.

\section{Metodologia}

O presente trabalho discorre sobre um curso de formação continuada construído e aplicado com professores de Biologia tanto da rede pública como da rede privada, gratuito e totalmente a distância. Os docentes interessados em realizar o curso sobre Genética na Atualidade efetuaram sua inscrição em um formulário online criado em uma ferramenta do gerenciador de e-mail (Gmail). O curso disponibilizava 40 vagas e contou com o atendimento de tutoria para auxiliar nas atividades e no acesso e navegação pelo ambiente virtual de ensino-aprendizagem (AVEA) livre Moodle (Modular Object-Oriented Dynamic Learning Environment).

O curso teve duração de aproximadamente dois meses e meio, com carga horária de 45 horas. As atividades do curso eram postadas semanalmente ou a cada duas semanas, de acordo com a proposta. As atividades tratavam de diferentes tópicos dentro da Genética na Atualidade, e para a execução das tarefas os professores cursistas utilizavam alguma ferramenta diferenciada que havia sido abordada no curso. Dentre as atividades que os professores cursistas realizaram podemos destacar: construção de cartoons, proposta de jogos didáticos, construção de folder e fotografias, entre outras. Os docentes recebiam a proposta da atividade sempre com materiais de apoio, e quando se tratava de um novo recurso para realizar a atividade era construído um tutorial com passo a passo auxiliando o professor.

Em determinados momentos, os professores cursistas apresentavam dúvidas para postar alguma atividade ou até mesmo para realizá-la; solicitavam então auxílio por meio de mensagens do Moodle ou pelo e-mail do curso criado pelo Google Mail (www.gmail.com). O curso alcançou professores do Estado do Rio Grande do Sul em maior representatividade da região central do estado.

Por fim, realizamos entrevistas com alguns docentes que tiveram diferentes atuações no decorrer do curso objetivando investigar as opiniões referentes à formação continuada a distância.

Este estudo foi realizado com um grupo de docentes matriculados em um curso de formação continuada na modalidade a distância para professores de Biologia.

Após o término do curso, buscamos representantes de três diferentes formas de participação:

- PI - Professor inscrito: professores matriculados no curso, mas que nunca realizaram nenhuma atividade, nem mesmo entraram na plataforma Moodle. 
- PE - Professor evadido: professores que iniciaram, mas evadiram no decorrer do curso.

- PC - Professor concluinte: professores que finalizaram o curso.

Entramos em contato com professores de cada um desses grupos para realizar uma entrevista buscando coletar informações referentes a cursos de formação continuada em EaD. Optamos por entrevistar docentes de diferentes cidades e das redes pública e privada.

As entrevistas envolveram cinco professores cursistas, dois PI, um PE e dois PC. Dentre os ambientes das entrevistas sugeridos pelos próprios cursistas, procuramos um lugar sem interrupções e distrações, além de ser um local em que o entrevistado se sentisse confortável (sala de aula da escola, laboratório na universidade etc.).

O modelo de entrevista utilizado nesta pesquisa foi semelhante ao desenvolvido no trabalho de Tolentino-Neto (2003). Buscamos realizar as entrevistas da forma mais espontânea, em que fluísse uma conversa sobre o curso de formação continuada a distância entre o entrevistado e os entrevistadores; a coleta de dados foi realizada por meio de entrevistas trianguladas.

\subsection{Entrevista triangulada}

O formato da entrevista segue o padrão de dois entrevistadores e um entrevistado (professor cursista), com alternância nas indagações entre os entrevistadores.

Para iniciar as entrevistas, atentávamos para a posição em que iríamos sentar, buscando que os dois entrevistadores ficassem lado a lado e o entrevistado ficasse na frente dos dois, dispondo em um formato triangular; desse modo, todos estavam na mesma posição, dependendo do ângulo observado, permitindo que o entrevistado tivesse interação com ambos os investigadores sem priorizar a atenção em apenas um entrevistador.

Antes de realizar as entrevistas, formulamos um guia para auxiliar nos questionamentos; esse guia foi planejado e construído pelos dois entrevistadores. A construção desse guia foi semelhante a algumas questões norteadoras utilizadas por Garcia (2012). No guia, separamos três blocos de questionamentos; o primeiro voltado ao perfil docente, como: formação inicial e em nível de pós-graduação, tempo de docência, carga horária, cidade(s) em que lecionava, quantas instituições, níveis de ensino e número de turmas em que trabalhava no decorrer do curso. O segundo bloco de questões referia-se à formação continuada, indagações como frequência de participação, experiência em formação em EaD, opinião sobre a modalidade a distância na formação continuada, diferença para cursos presenciais e dedicação na modalidade a distância, entre outros questionamentos pertinentes à formação continuada. O último bloco de questões era referente ao curso EaD de Genética na Atualidade; este último bloco levantava opinião dos docentes sobre diversos aspectos de atividades, como tempo, dificuldades e motivações, entre outros quesitos relacionados ao curso.

Vale destacar que algumas perguntas foram comuns nos três grupos de entrevistados e outras foram específicas, destacando as diferentes formas de participação.

\subsection{Aspectos técnicos da videogravação}

Nesta pesquisa aprimoramos uma técnica de entrevista, com vista a melhorar a observação e aprimorar os métodos de coleta de dados, contribuindo para o desenvolvimento de métodos que auxiliem o meIhor entendimento da realidade estudada. Por esse caminho, verificamos primeiramente a definição de entrevista de pesquisa "como uma técnica em que o investigador se apresenta frente ao investigado e lhe formula perguntas, com o objetivo de obtenção dos dados que Ihe interessam a investigação" (Gil, 2010, 
p. 109). Assim, desenvolvemos a discussão proposta por meio da análise da aplicabilidade da entrevista, em especial a forma de abordagem do entrevistador, de maneira que possamos verificar os depoimentos como coletas de dados produzidas sobre condições específicas nas quais podemos considerar alguns dos elementos que irão compor essa situação de interação. De acordo com Belei et al. (2008, p. 192), a coleta de dados por meio de gravação de vídeo apresenta inúmeras vantagens, permitindo a captação de sons e imagens que reduzem muitos aspectos que podem interferir na fidedignidade dos dados observados.

Para proporcionar ao entrevistador mais habilidade na condução da entrevista, é imprescindível fazer a construção prévia de um guia de perguntas, o qual auxiliará no objetivo de pesquisa, permitindo criar uma adequação em termos de linguagem, estrutura e sequência das perguntas, alertar sobre o objetivo das informações que serão coletadas, o direito ao sigilo profissional, assim como a interrupção da entrevista. Pelo Termo de Consentimento de Livre Esclarecimento, declarar que as informações foram passadas de forma apropriada e voluntária, com o Consentimento Livre e Esclarecido desse sujeito de pesquisa para a participação neste estudo.

O posicionamento do videogravador e a utilização de pastas para o guia de perguntas são importantes cuidados que se deve ter em relação ao investigado para evitar qualquer tipo de preocupação com tempo e desconforto, de modo que a entrevista possa fluir de forma tranquila e de maneira espontânea, incentivando a liberdade para expressão das ideias.

A videogravação é um recurso bastante utilizado em pesquisas qualitativas; muitos pesquisadores optam por transcrever as gravações na íntegra, transformando o texto audiovisual em texto escrito para posteriormente analisá-lo.

De acordo com Pinheiro, Kakehashi e Angelo (2005), o uso de uma câmera fixa possibilita deixar o equipamento operando por um tempo mais longo, sendo recomendado para apreensão de imagens e sons de fenômenos com ocorrência natural. Nesse caso, as entrevistas foram gravadas em áudio e vídeo com a utilização de um notebook com câmera fixa; o programa utilizado para as gravações foi My Cam, gratuito. Um dos critérios importantes na escolha do programa está no tempo limite de filmagem, para evitar que as gravações não sejam interrompidas pelo programa. Também foi necessária a realização de um pré-teste para definir o tempo de gravação e o posicionamento do computador, a fim de adequar à acústica do espaço e deixar o computador não tão próximo para evitar algum tipo de constrangimento.

\subsection{Entrevista triangulada com videogravação}

Primeiramente, explicamos aos entrevistados que o motivo da gravação era pelo áudio, caso precisássemos resgatar alguma opinião pertinente sobre o curso, buscando ser o mais fidedigno possível. Além disso, as gravações poderiam ser utilizadas para obter algumas transcrições literais das falas dos professores, caso fosse necessário. Optamos por filmar as entrevistas para nos dedicarmos à conversa sem necessidade de escrever as respostas, de modo que poderia deixar o entrevistado inibido ou até mesmo perder informações importantes. As gravações serviram para que pudéssemos retomar as informações necessárias para confeccionar uma síntese com as respostas dos entrevistados.

Antes de iniciar a entrevista, conversávamos com o docente explicando o porquê daquele momento, a sua importância. O entrevistado recebia o Termo de Livre Consentimento Esclarecido para ler e assinar, se concordasse em participar da entrevista.

Os entrevistadores questionavam alternadamente o docente, evitando interrupções; o entrevistador que não estava questionando naquele momento olhava o guia para verificar se havia algum questionamento essencial que ainda não havia sido perguntado; não havia rigor a ser seguido, assim como não existia uma ordem certa das perguntas; e poderiam surgir indagações além das que estavam no guia sem nenhum problema. 
De acordo com a bibliografia, existem diferentes tipos de entrevistas; conforme Manzini (2012), as entrevistas podem ser classificadas em: estruturada, semiestruturada e não estruturada. A entrevista que realizamos pode ser classificada como semiestruturada, uma vez que, conforme o autor, esse tipo de entrevista apresenta perguntas abertas destinadas a estudar um grupo específico, no nosso caso um grupo de educadores, existindo flexibilidade na sequência das perguntas, podendo ser feitas perguntas complementares ao entrevistado.

Após o encerramento da entrevista e a ausência do entrevistado no ambiente, os entrevistadores dialogavam e construíam um relato acerca das informações das entrevistas, da opinião do educador sobre o curso EaD; essa síntese era discutida e construída com o olhar de duas pessoas, evitando assim um relato tendencioso e objetivando ser o mais fiel à opinião do entrevistado. Como optamos por gravar, poderíamos assistir às entrevistas quantas vezes fossem necessárias para evitar qualquer tipo de dúvida a respeito da opinião do cursista entrevistado. Dessa forma, tínhamos a redundância de informações necessárias para a construção de um relato fidedigno das falas dos entrevistados.

Como sugerido por Belei et al. (2008), muitas vezes é preciso mais de uma pessoa para observar e registrar ao mesmo tempo, devendo haver concordância entre os registros, tornando a entrevista mais confiável.

A escolha por esse modelo de entrevista, em que não se utilizam anotações na hora nem se redigem todas as falas, teve o intuito de permitir um maior envolvimento do entrevistado, deixando-o mais à vontade. Acreditamos que, fluindo de maneira mais natural, diminuiríamos as inconsistências e os ruídos de interpretação. Consideramos que obtivemos respostas com maior confiança e fidedignidade dos relatos coletados sobre a real opinião dos professores frente a formações a distância. Os dados das entrevistas foram analisados de maneira qualitativa.

\section{Resultados e Discussão}

Entrevistamos cinco professores cursistas: dois PI (professores inscritos, mas que não participaram e não acessaram o ambiente virtual do curso), um PE (professor evadido) e dois PC (professores concluintes).

As entrevistas tiveram durações diferentes, variando de 17 minutos (a de menor duração) até 57 minutos, dependendo de cada entrevistado; todos mostraram-se a desinibidos e agiram com naturalidade durante as falas com os entrevistadores. As entrevistas trianguladas ocorreram como uma conversa em um ambiente escolhido pelo próprio entrevistado, deixando-o à vontade, sem nenhuma avaliação ou punição, com sigilo profissional e liberdade de interromper a entrevista se assim desejasse.

Com base nas entrevistas, selecionamos diferentes questões referentes ao perfil dos profissionais, opiniões acerca da EaD e do curso de formação continuada Genética na Atualidade.

\section{a. Perfil dos professores cursistas}

Dentre os cinco professores entrevistados, quatro são mulheres; quatro deles têm entre quatro e seis anos de docência, o que caracteriza um grupo feminino e iniciante na carreira. É um grupo uniforme no que diz respeito à formação inicial formal, já que todos os docentes são licenciados em Ciências Biológicas; os cinco entrevistados apresentam formação em algum nível de pós-graduação, já concluído ou em andamento (especialização e/ou mestrado e/ou doutorado).

Três dos professores desta pesquisa trabalhavam em mais de uma instituição; dois docentes, em apenas uma. Em relação à carga horária dos docentes, dois tinham 60 horas semanais; os demais apresentavam 20, 30 ou 40 horas. 


\section{b. Interesse pelo curso}

Os motivos que levaram os professores a se inscrever no curso foram: interesse pela temática "genética na atualidade"; todos os educadores entrevistados sentiram-se motivados a realizar o curso devido ao tema proposto; a busca por novos conhecimentos; atualizações e o fato do curso ser totalmente EaD foram outros atrativos que influenciaram a inscrição no curso. Os resultados desta pesquisa são semeIhantes aos de Garcia (2012), que apresenta em seu trabalho que os principais interesses pela participação no curso de Educação Nutricional foram: o tema, a busca por novos conhecimentos e a flexibilidade de horários possibilitada pela EaD.

\section{c. Se o curso fosse presencial...}

Os educadores foram questionados: três professores - PI1, PE e PC2 - afirmaram que, "se o curso fosse presencial..." não teriam participado, pois seria inviável. PI2 teria interesse e tentaria participar presencialmente; PC1 afirma que conseguiria participar. O fato de o curso ser a distância auxiliou na participação dos professores; em outra opção de modalidade, não teriam conseguido realizar o curso de formação continuada. Vale ressaltar que o curso foi realizado da cidade de Santa Maria-RS e alcançou professores de outras cidades do estado.

O depoimento de PC2 mostra tal situação sobre o fato do curso ser EaD, e não presencial:

No meu caso, o curso em EaD facilitou muito; citando o exemplo do ano passado: como eu ia toda semana para São Paulo, se eu não tivesse oportunidade de fazer o curso a distância, eu não teria conseguido fazer presencial. Para mim foi ótimo.

No momento da entrevista, alguns docentes destacaram que seria interessante ter encontros presenciais ao longo do curso. Dentre as sugestões que apareceram de situações presenciais estão: PI1 acredita que deveria ter um encontro presencial no início do curso, a fim de conhecer os colegas e ter explicações gerais acerca do curso; PI2 e PC1 destacaram também que encontros presenciais poderiam enriquecer o curso para troca de experiências, uma vez que dificilmente esses momentos ocorrem entre colegas da mesma disciplina nas escolas que trabalham, por incompatibilidade de horário. Muitos cursos fazem encontros presenciais apenas para realização de provas/avaliações; no curso descrito por Garcia (2012), das 60 horas de curso 58 eram a distância e duas horas eram presenciais para realizar avaliações finais, não ocorrendo um momento destinado à interação entre os educadores. Os professores que sugeriram momentos presenciais viam com o viés de troca de experiências com os colegas de disciplina, e não apenas um encontro para realizar uma atividade.

\section{d. Possibilidades e caminhos da EaD}

O ensino a distância tem se expandido de modo significativo, e o preconceito e a desvalorização com essa modalidade de ensino têm diminuído. Porém, para concluir um curso em EaD com êxito é necessário empenho e dedicação, uma vez que essa modalidade permite flexibilidade, exigindo assim organização e autonomia.

O depoimento dos cursistas ilustra essa situação.

Acho que já teve mais preconceito com cursos em EaD, hoje em dia acho que não, e eu admiro quem consegue seguir um curso a distância, porque eu sou uma que sou difícil de me policiar a fazer, acabo deixando para última hora, eu acho que tu precisa de muito mais disciplina para fazer um curso em EaD do que um presencial, porque presencial 
tu sabe que tem que ir na aula, fazer isso e aquilo; no EaD tu depende de ti e da tua organização (PI2).

Um dos docentes entrevistados destacou também a importância das cobranças por parte dos cursos em EaD, além de destacar a flexibilidade que essa modalidade permite.

O curso a distância vai muito da maturidade de cada pessoa, tem gente que acha que é barbada porque é um curso a distância... Tu vai ter um certificado de curso a distância, curso a distância qualquer um faz! (...) Não é assim, eu não vejo assim, por que tu tem que fazer as atividades, claro que a gente espera que alguém vá cobrar isso... Acho que o curso a distância é algo que facilita... Eu faço no tempo que tenho livre, se fosse um curso presencial com horário fixo não sei se conseguiria... (PI1).

A maturidade destacada pelo docente entrevistado vai ao encontro do estudo de Palloff e Pratt (2003), que destacam que o estudante virtual bem-sucedido é normalmente pessoa de mais idade e mais madura, que se organiza sem cobranças. Na visão de Santos e Campos (2016), a EaD deve expandir junto à educação superior brasileira e deve fazer parte das políticas públicas de formação inicial e continuada de professores, uma vez que a modalidade apresenta-se como uma possibilidade de amparo à formação continuada para docentes.

Coelho e Monteiro (2017) apontam a evolução que a EaD sofreu; essa, que era uma modalidade desacreditada, tornou-se uma ótima opção de formação inicial e continuada para docentes; os pesquisadores ressaltam ainda que são necessárias a inserção digital e a vontade de aprender.

\section{e. Flexibilidade de horários}

Dentre as várias possibilidades da EaD, os discursos dos docentes destacaram ao longo das entrevistas a questão do tempo, que o ensino a distância facilita no processo de formação continuada, permitindo que o cursista faça as atividades nos horários disponíveis, ainda mais tratando-se de um grupo de professores que apresentam muitas vezes pouca disponibilidade de tempo.

O curso a distância é ótimo, pois meu tempo é escasso, então tu acessa a hora que tu pode e dentro do prazo da atividade de uma ou duas semanas tu te programa e consegue desenvolver uma atividade que já pode ser usada para diferenciar em sala de aula (PC1).

Eu sempre fui a favor da EaD, desde que eu trabalhei em um curso como tutora da EaD eu gostei muito, eu acho que tem cursos e cursos, tem cursos em EaD que você vê que não é positivo, que não tem tanto contato com o aluno, ou fica mais perdido, alguns de que já havia tido referência, depende muito do aluno e da equipe envolvida, se tem envolvimento dos tutores, se tem envolvimento dos alunos. É um crescimento para a gente pode conciliar horários e poder te qualificar... Assim como tem cursos presenciais que não são bons cursos, assim vai ser na EaD também, os dois cursos têm a mesma função de conhecimento (PC2).

De acordo com Santos e Campos (2016), a formação de professor por meio da EaD emerge como política pública nacional em que deve ser oferecida formação continuada para professores em serviço com um olhar sobre a flexibilidade de horários que a modalidade a distância propicia, devido à alta demanda de carga horária investida pelos docentes. 


\section{f. Época do ano}

Ao verificarmos os posicionamentos em relação à época do ano em que o curso Genética na Atualidade foi realizado $\left(2^{\circ}\right.$ semestre do ano), foi possível perceber que PI1, PI2, e PC2 consideram que o início do ano seria melhor, devido à sobrecarga de final de ano e por acreditarem que o primeiro semestre na escola é um período mais calmo. Contudo, para os professores PE e PC1 o final de ano teria sido um bom momento para a realização do curso, pois poderiam repensar suas práticas pedagógicas do ano letivo e já se programar para o próximo ano, e por se tratar de um período em que os professores estão mais cansados e precisariam de motivações e sugestões para diferenciar e criar suas aulas.

\section{g. Rotina docente e a realização concomitante de curso de formação continuada em EaD}

Os depoimentos de todos os professores entrevistados acerca da sua rotina docente e a realização do curso concomitantemente destacam que uma prática não prejudicou a outra. Quando questionamos PC1 se o curso atrapalhava sua rotina docente, a resposta que obtivemos foi: "De forma alguma; pelo contrário, me auxiliou, inclusive, porque um dia lá, eu posso fazer a atividade do curso e não preciso preparar a aula naquele dia. Eu já tinha atividade pronta que eu iria fazer". Nesse caso, podemos observar que o curso colaborou com as práticas pedagógicas e auxiliou na preparação de materiais das atividades realizadas em sala de aula.

Conforme destacam Salvador e colaboradores (2012), a formação continuada com uso de tecnologias pode auxiliar o professor a incorporar essas ferramentas na sua aprendizagem e no ensino.

\section{h. Duração do curso}

A escolha pelo tempo de duração do curso, de aproximadamente dois meses e meio, foi baseada no curso realizado e descrito por Garcia (2014), que teve duração de nove semanas.

Questionamos então os professores sobre tempo de curso proposto. PI1, por não ter participado do curso, preferiu não opinar; PI2 julgou adequado, por não ser tão longo e cansativo. Já PE, PC1 e PC2 julgaram como adequado, porém os três afirmaram que a duração poderia ser maior para apresentar mais possibilidades de ferramentas virtuais.

\section{i. Sobre participação em cursos em EaD}

Como observamos nos depoimentos dos professores, todos já haviam participado de cursos em EaD e afirmaram que fariam novamente cursos nessa modalidade. Portanto, é possível perceber que essa modalidade obteve bastante aceitação e novamente se mostrou uma ótima opção para a formação continuada de professores. Dessa forma, esses dados se mantêm em concordância com os trabalhos de Salvador et al. (2010), que apresentaram em seu trabalho aumento na procura por cursos em EaD com o passar dos anos, mostrando aceitação e interesse dos educadores em realizar formação continuada na modalidade. Coelho e Monteiro (2017) sinalizam que formações em EaD apresentam grande potencial, uma vez que permitem a participação de grande número de profissionais voltados para processos continuados de formação e podem desenvolver laços articulados à realidade em que trabalham.

\section{j. Motivos das evasões}

Uma preocupação constante na EaD são os níveis de evasão. Para Favero (2006), é considerada evasão qualquer desistência ao longo do curso, até mesmo daqueles que nunca se manifestaram de qualquer forma.

Dos cinco docentes entrevistados, três deles são evadidos; dois (PI1 e PI2) se inscreveram no curso, mas jamais realizaram uma atividade, nem mesmo acessaram a plataforma Moodle; um professor (PE) evadiu no decorrer do curso, realizando apenas as atividades iniciais. 
Quando esses professores foram questionados sobre o motivo da evasão, a justificativa foi a falta de tempo, pois tinham muitos compromissos com as atividades docentes. Os docentes que evadiram não comunicaram que não continuariam no curso; apenas não respondiam às mensagens e atividades propostas.

Branco e Oliveira (2008) destacam em suas pesquisas que a falta de tempo para dedicação ao curso de formação está relacionada com o excesso de trabalho docente. Favero (2006) aponta que uma das grandes causas da evasão é o cansaço dos educadores após um dia de trabalho; essa exaustão acaba comprometendo a aprendizagem e desmotivando a participação.

Os motivos de evasão dos professores entrevistados coincidem com a pesquisa de Branco e Oliveira e com a de Favero; o acúmulo de serviço e a falta de tempo para dedicar-se levam os cursistas a abandonar os cursos.

É de suma importância ter atenção especial para as taxas de evasão nos cursos em EaD; esse é um problema que deve ser observado a fim de minimizar cada vez mais essas taxas; conforme o Censo EaD.br de 2015, com publicação no ano de 2016, a taxa média de evasão foi de $26 \%$ a 50\%, com 40\% em cursos totalmente EaD; o relatório aponta que o fator do tempo é o maior responsável pela evasão, seguido do fator financeiro. É maior obstáculo da modalidade, e diminuir esse índice é um desafio.

\section{Considerações Finais}

A formação inicial dos professores de Biologia deve ser complementada com cursos de formação continuada. A modalidade Educação a Distância mostrou-se uma opção viável e de interesse dos docentes entrevistados neste trabalho. Carga horária elevada, escassez de tempo, dificuldade de deslocamento, docência em diferentes instituições são alguns dos motivos que dificultam a participação dos professores em cursos de formação continuada na modalidade presencial, pois ocorre incompatibilidade de horários para esses momentos formativos.

Desse modo, o curso de formação continuada em EaD agiu como facilitador no processo de formação, porém para essa modalidade de estudo é necessário organização, autonomia e motivação para seguir. Com base nos resultados obtidos nesta pesquisa, percebemos que a temática do curso é um grande fator motivante que deve ser considerado para construções de cursos em EaD.

A carreira do magistério é caracterizada por grande sobrecarga de trabalho, pois além de ministrar aulas os docentes têm envolvimento no planejamento de atividades extraescolares, sendo um desafio realizar formações continuadas. A desistência em atividades formativas presenciais ou a distância são limitações encontradas ao trabalhar com grupo de docentes em que, ao longo do ano, os fatores de sobrecarga vão se intensificando, como acúmulo de tarefas, fechamento de notas, múltipla jornada de trabalho, seguidos por desvalorização e baixos salários. Esses são fatores agravantes que levam os professores a optar, pelo cansaço e falta de tempo, por abandonar atividades formativas que exigem trabalho extra.

A evasão é um dos maiores desafios da EaD, e por isso merece atenção especial com o intuito de evitar desistências ao longo da formação; algumas medidas podem diminuir essas taxas. Dentre as possibilidades de minimizar a evasão podem ser consideradas algumas propostas, como a presença de um tutor motivando os cursistas e auxiliando nas atividades e ferramentas para quando surgem dúvidas; durante o curso as tarefas podem ficar abertas sem data limite, para que o professor consiga realizá-las e postá-las sem que tenha o sentimento de ter perdido prazos e assim evadindo; estímulo às interações entre os cursistas; utilização de tutoria com o passo a passo facilitando a utilização de ferramentas novas; foi sugerido que o curso não tenha duração muito extensa, para que não se torne cansativo. 
Os resultados deste trabalho podem auxiliar na construção de novos cursos em EaD, favorecem uma reflexão acerca de possibilidades e desafios da formação continuada dos docentes por essa modalidade, buscando cada vez mais uma maior adesão, assim como tentativas para superar as dificuldades encontradas com a evasão.

\section{Agradecimentos}

Este artigo é parte de uma pesquisa de mestrado defendida em 5 de maio de 2016 no Programa de Pós-Graduação em Educação em Ciências da Universidade Federal de Santa Maria (UFSM); por essa razão, agradecemos à Capes e à UFSM pelos auxílios concedidos, que foram de substancial importância para a realização desta pesquisa.

\section{Referências Bibliográficas}

Associação Brasileira de Educação a Distância - ABED (2016). Censo EAD.BR: relatório analítico da aprendizagem a distância no Brasil 2015. Curitiba: InterSaberes.

Branco, J. C. S. (2008). A educação a distância para o professor em serviço. Dissertação de Mestrado em Educação Tecnológica. Centro Federal de Educação Tecnológica de Minas Gerais.

Brasil (1996). Lei n 9.394, de 20 de dezembro de 1996. Estabelece as Diretrizes e Bases da Educação Nacional. Brasília: Presidência da República. Disponível em http://www.planalto.gov.br/ccivil_03/leis/l9394.htm.

Belei, R. A. et al. (2008). O uso de entrevista, observação e videogravação em pesquisa qualitativa. Cadernos de Educação, FAE/PPGE/UFPEL, Pelotas, v. 30, p. 187-199, jan/jun.

Belloni, M. L. (2003). Educação a distância. Campinas: Autores Associados.

Bonzanini, T. K. \& Bastos, F. (2009). Formação continuada de professores: algumas reflexões. In Encontro Nacional de Pesquisa em Educação em Ciências, 7. Florianópolis.

Coelho, F. J. F. \& Monteiro, S. (2017). Educação sobre drogas: possibilidades da EaD na formação continuada de professores. EaD em Foco, 7(2), 194-204. http://dx.doi.org/10.18264/eadf.v7i2.577

Favero, R. V. M. (2006). Dialogar ou evadir: eis a questão! Um estudo sobre a permanência e a evasão na Educação a Distância. Dissertação de mestrado em Educação. Universidade Federal do Rio Grande do Sul.

Garcia, P. S. \& Bizzo, N. (2012). As motivações de professores de Ciências para a formação contínua a distância. Revista Educação em Questão, UFRN, 44, 165-194.

Garcia, P. S., Bizzo, N. \& Fazio, X. (2014). Desafios da formação contínua a distância para professores de ciências. RIED. Revista Iberoamericana de Educación a Distancia, 17, nº 2, 37-57, 2014.

Gil, A. C. (2010). Métodos e técnicas de pesquisa social. 6ª ed. São Paulo: Atlas.

Manzini, E. J. (2012). Uso da entrevista em dissertações e teses produzidas em um programa de pósgraduação em educação. Revista Percurso - Nemo, Maringá, 4, nº 2, p. 149-171.

Palloff, R. M. \& Pratt, K. (2003). The virtual student: a profile and guide to working with on-line students. San Francisco: Jossey-Bass Pfeiffer.

Pinheiro, E. M., Kakehashi, T. Y. \& Angelo, M. (2005) O uso de filmagem em pesquisas qualitativas. Rev Latino-am Enfermagem, 13(5), 717-722, set./out. 
Salvador, D. F. et al. (2012). Colaborar para aprender e avaliar para formar: um relato de experiência na formação continuada de professores de Biologia. Revista Brasileira de Aprendizagem Aberta e a Distância, 11, 35.

Salvador, D. F. et al. (2010). Um panorama da formação continuada de professores de Biologia e Ciências através da EaD no Estado do Rio de Janeiro. Revista EaD em Foco, 1(1), 59-68. DOI: http://dx.doi. org/10.18264/eadf.v1i1.19.

Santos, C. S. S. \& Campos, G. H. B. (2016). Caminhos da Política Nacional de Formação de Professores na Modalidade a Distância. Revista EaD em Foco, 6(1), 69-86. DOI: http://dx.doi.org/10.18264/eadf.v6i1.332.

Tolentino-Neto, L. C. B. (2003). O processo de escolha do livro didático de ciências por professores de $1^{a} a 4^{a}$ séries. Dissertação de mestrado em Educação. Faculdade de Educação, Universidade de São Paulo. 